\title{
Better communication is in everyone's interests
}

\section{Scientists will find it's worth making the effort to explain what they're doing to the public.}

Sir-If science communicators, as characterized by Steve Fuller in Correspondence ("Communication should not be left to scientists”, Nature 416, 475; 2002), are members of a "mediating profession", then teachers must surely be too.

Science reporters and producers writing or broadcasting stories about science - provide most of society with its adult science education. They are intermediaries between scientists and the public, two groups who rarely meet face to face. We institutional press and publicaffairs officers, as you rightly suggest in your Opinion article in the same issue (Nature 416, 461; 2002), often provide the conduit for communication between scientists and science writers and editors.

Effective science communication requires a jack-of-all-tradesmanship uncommon in other, more specialized fields. Science communicators need to understand and interpret the scientific process and its fruits; to grasp at least the rudiments of myriad disparate disciplines of study; to translate scientific jargon into language a lay audience can understand; and to persuade editors and producers that stories warrant space or time. We are like diplomats, deftly shuttling back and forth between foreign cultures.

I was not formally trained in the sciences. If scientists can explain their work to me such that I understand it, and even go a step further and imbue me with their enthusiasm for the research, I can develop a story that will interest, intrigue and inform editors and, in turn, their readers, viewers or listeners.

This is a collaborative process in which the scientist not only submits to an interview, but also reviews drafts for accuracy. It is a time-consuming process: for the scientist, this means time taken away from his or her research. Scientists might ask whether it is worth it, and what's in it for them.

The ready answer is: recognition in the form of favourable publicity, with increased chances of funding. A more high-minded response could be the importance to civilized societies of a well-informed populace.

Public-relations professionals science communicators among them promote their clients' work rather than their own, which may be why we're not widely appreciated. Derisive nicknames like 'spin doctor' derive from the politicians you aptly credit with media savvy in your Opinion article. 'Spin' refers to nothing more nefarious than the angle from which a story is told to convey the desired message.

Among other misperceptions about public relations is the belief that the practice requires no special skills and that anybody can do it. I once heard the president of a prominent US publicrelations company assure his employees that what they do "is not brain surgery" nevertheless, it is not child's play either.

The prerequisite to successful professional communication is the ability to communicate well and creatively, in speaking and writing. Understanding how the media work — including knowing the sort of story most likely to be published, being sensitive to deadlines and using tactics intended to make journalists' jobs easier — is key, as is the ability to apply strategies for managing crises and controversies.

By following your recommendation that they take a more active role in telling the "real" story, scientists will help to solve some of the genuine problems besetting science communication.

For instance, most of what constitutes science coverage in major newspapers and consumer magazines are medical and health stories. (All the examples in your editorial are medical.) It is human nature for people to be most interested in what affects them personally. The greatest challenge by far to science public-affairs officers is finding a way to interest editors in research that does not have an immediately apparent consequence for their readers.

"Significant breakthroughs" are the only other aspects of science widely considered to be newsworthy; hence the exaggerated claims made in some press releases. People raised in the twentieth century have learned to think of science in terms of amazing discoveries, their imaginations captivated by space exploration or developments in technology that improve their daily lives. Such an audience is less easily moved by the fine points of the disciplines within my purview, such as evolution, ecology, systematics and taxonomy. But it can be done and it can be done well, without diluting the quality or integrity of the science, if scientists construct a broader, more popular frame of reference for their research.

Science communicators are trained and experienced in this line of thinking and can help. Working together, we can make science more accessible and more highly valued by the people it informs and serves. Elizabeth J. Tait

Office of Public Affairs, Smithsonian Institution, 1000 Jefferson Drive, Southwest, Washington, DC 20560-0033, USA

\section{Boycott of Israel? It worked for South Africa}

Sir — We would like to make it clear (see Opinion, Nature 417, 1; 2002) that in our petition we are calling not for a boycott of individual scientists in Israel but for a suspension of institutional links until Israel complies with UN resolutions and begins to negotiate seriously with its Arab neighbours along the lines of the Saudi and other similar peace plans.

You argue that such sanctions are ineffective and that Mr Sharon will lose no sleep over them. Nevertheless, the peaceful boycott by the world's academic and cultural communities was instrumental in ending apartheid in South Africa.

If to make our demand is to be partisan, so be it - peace and justice demand partisanship. Israeli researchers may well find this prospect unpalatable, but some in Israel have selflessly given their support. Many of the signatories of our letter are receiving torrents of hate e-mail, especially if they are Jewish, being accused of everything from anti-semitism to support for terrorism. Such allegations conflate uncritical support for the Israeli state with Jewish identity, and are both repugnant and unjust.

Finally, we would like to point out that all authors of our petition signed in their personal capacity; institutional affiliations were given for identification purposes only.

Steven Rose ${ }^{\star}$, Hilary Rose $\dagger$

${ }^{*}$ Department of Biological Sciences, The Open University, Milton Keynes MK7 6AA, UK $\dagger$ City University, 4 Lloyd Square, London WC1X 9BA, UK

\section{Palestinian scientists are already restricted}

Sir - Your Opinion article "Don't boycott Israel's scientists” (Nature 417, 1; 2002) expresses concern that a European boycott of Israeli scientists will harm three-way collaboration involving Palestinian scientists as well. This argument would 
have gained in cogency by including a

Palestinian perspective.

Were there reason to believe that Palestinian scientists could participate freely in such collaborations, unimpeded by arbitrary and unpredictable curfews imposed by an occupying army, denying them access to their own laboratories, not to mention European hosts, those of us who signed the call for a moratorium — not an unlimited boycott — might not have felt compelled to take such a drastic step.

Ahmed Abbes*, Mikhael Balabane*, Emmanuel Farjoun $\dagger$, Michael Harris $\ddagger$, Raphael Rouquier $\ddagger$, Pierre Schapira $\$$ *Université Paris 13, 99 Avenue Jean-Baptiste Clément, 93430 Villetaneuse, France $\dagger$ Hebrew University of Jerusalem, Jerusalem 91904, Israel $\ddagger$ Université Paris 7, 2 place Jussieu, 75251 Paris Cedex 05, France §Université Paris 6, 75252 Paris Cedex 05, France

\section{Efforts to build bridges in the Middle East}

Sir - I was delighted to see the Opinion article "Don't boycott Israel's scientists" (Nature 417, 1; 2002).

I do not pretend to be impartial: my father, his brother and sister survived the Shoah, but the entire rest of his family (more than 30 aunts, uncles and cousins) perished; I have spent each of my sabbaticals partly in Israel, have sponsored students and post-docs from Israel, and have binational science foundation grants.

I also serve on the Science Advisory

Board of the Arava Institute of

Environmental Studies, which attempts to simultaneously do good science and build bridges between Israel and its Arab neighbours.

I count Patrick Bateson as one of my friends and grieved to see him leading the UK scientists in the direction of a boycott.

Your Opinion article beautifully articulates the reasons for continuing to support Israeli science.

Marc Mangel

Department of Environmental Studies, 39 Natural Sciences 2, University of California, Santa Cruz, California 95064, USA

\section{Taxonomists need better access to published data}

Sir - The biodiversity community must learn from its counterparts in the physical and biomedical sciences and move towards the provision of unhindered access to its baseline data: taxonomic descriptions, imagery, geographical and temporal distribution, and characters - molecular, morphological and behavioural (see H. C. J. Godfray's Commentary "Challenges for taxonomy”, Nature 417, 17-20; 2002).

International codes of nomenclature require taxonomic actions to be published, and the data thus made available. Yet much of the underlying information is accessible only by examination of the specimens involved, so access is in effect limited to all but a few potential users. The assertion of copyright by publishers further limits the distribution of published information.

Very few libraries around the world have the financial capacity to carry the full range of literature in which systematic results are published. To take the ants as one example, the 11,000 species were first formally described in approximately 3,800 publications - roughly 100,000 printed pages — in more than 800 serials and monographs.

As F.-T. Krell noted in Correspondence (Nature 415, 957; 2002), the relevance of taxonomic publications remains high for many years. Although funding has been secured to make $80 \%$ of the ant pages accessible online within the next two years at www.antbase.org (see Nature 416, 115; 2002), many recent papers are not in the public domain because of publishers' copyright restrictions.

To chart even the $1-1.5$ million "known" species of the world (E. O. Wilson, Science 289, 2279; 2000) is a daunting task. International initiatives such as the Global Biodiversity Information Facility are needed to help people work effectively towards that goal, as are the development of tools from information technologies and a new cultural approach to ownership and sharing of data.

In the genomics community, authors place all sequence data in a publicly accessible depository. As a result, the data themselves can be peer-reviewed, and new areas of investigation have developed through comparison and collation of data sets.

The biodiversity and conservation communities would greatly benefit from similar provision of open access to character and distributional data. Because of space and cost constraints, many of these data are unpublished. We sorely need a mechanism to provide access to these data, along the lines of GenBank, as well as the cultural imperative to deposit data (see Godfray's Commentary for a proposal to make taxonomy a web-based unitary discipline).

For now, it would be a tremendous benefit if publishers would make published taxonomic papers open-access, so that an equivalent to PubMed can make this important scientific information available to the broadest possible community.

Donat Agosti ${ }^{\star}$, Norman F. Johnson $\dagger$

${ }^{\star}$ American Museum of Natural History, New York, New York 10024-5192, USA

$\dagger$ Insect Collection, Ohio State University,

Columbus, Ohio 43210-1220, USA

\section{Advocacy and analysis}

Sir - Roger A. Pielke, in his Commentary "Policy, politics and perspective" (Nature 416, 367-368; 2002) argues that scientists should not be advocates; that research should be communicated to society through policy analysts. Unlike the advocate, who subordinates science to one narrow vision of its social implications, he says that the analyst "increases the range of alternatives available to decision-makers by clearly associating scientific results with a range of choices and outcomes".

Pielke objects to natural scientists who simply advocate more research to help solve social problems - but he then argues something similar for his own form of science: social-science policy analysis. Pielke is right that more social-scientific research and analysis of science and its results would be beneficial. But with this argument, is he not as much an advocate as those he criticizes?

\section{Carl Mitcham}

Liberal Arts and International Studies, Colorado School of Mines, Golden, Colorado 80401, USA

\section{Specimen collecting is still vital for research}

Sir - The monumental data set assembled and analysed by Ernst Mayr and Jared Diamond in their monograph The Birds of Northern Melanesia, reviewed by Stephen Pruett-Jones (Nature 415, 959-960; 2002), was based in part on museum skin specimens obtained during general collecting expeditions over many years.

An unwillingness to acknowledge the role of specimens in scientific research is contributing to the deterioration of avian biodiversity collections and is hindering the thorough collecting that is so necessary for future studies. It has been argued that further collecting is unnecessary even in poorly inventoried areas, despite clear evidence to the contrary.

Seminal works such as Mayr's and Diamond's rely on specimen foundations in museums. It is essential to acknowledge this, so that the avian specimen base can be expanded, understood and supported. Angelo Capparella Department of Biological Sciences, Illinois State University, Normal, Illinois 61790-4120, USA 